\title{
Morphology and Properties of Nylon 6 Blown Films Reinforced with Different Weight Percentage of Nanoclay Additives
}

\author{
Raghavendra R. Hegde, ${ }^{1}$ Gajanan S. Bhat, ${ }^{1}$ and Bhushan Deshpande ${ }^{2}$ \\ ${ }^{1}$ Department of Materials Science and Engineering, The University of Tennessee, Knoxville, TN 37996-2200, USA \\ ${ }^{2}$ Techmer PM, Clinton, TN 37716, USA \\ Correspondence should be addressed to Raghavendra R. Hegde, indrahegde@gmail.com and Gajanan S. Bhat, gbhat@utk.edu
}

Received 2 November 2011; Accepted 9 February 2012

Academic Editor: Chantara Thevy Ratnam

Copyright (C) 2012 Raghavendra R. Hegde et al. This is an open access article distributed under the Creative Commons Attribution License, which permits unrestricted use, distribution, and reproduction in any medium, provided the original work is properly cited.

\begin{abstract}
This article presents the effect of increasing weight percentage natural nanoclay additives on the structure, morphology and mechanical properties of nylon-6-blown films. Combination of X-ray diffraction, thermal analysis and microscopy were used to determine nanocomposite film morphology. The nanoclay additives in the films act as nucleating agent facilitates $\gamma$-crystalline forms and results in fine grained spherulite with smaller lamellar size. Increase in tensile, burst, and tear strength is observed for films with up to $5 \%$ clay loading. Even though microscale property like tensile and tear strength drops at higher add on levels, nearsurface nanoscale hardness and toughness of the film keep on increasing. There is a direct correlation between nanoclay additive add on level and increase in surface energy and wetting behavior of films.
\end{abstract}

\section{Introduction}

In recent years, layered silicate nanocomposites have gained enormous research interest [1]. Continual studies have shown enhanced properties in final products derived by loading clay just as low as $0.5 \mathrm{wt} \%$ compared to conventional composite with large amount of micron size additives. The nanoclay dispersion is currently being used to improve modulus and tensile strength, barrier properties, flame resistance [2], lower flammability [3], and to improve thermal and structural properties of many plastics, instead of conventional fillers like metal, glass, and wood particles [4-8]. The natural nanoclay is approved by the U.S. Food and Drug Administration (FDA) for food contact and used as base for cosmetics, medicines, and pharmacology.

Nanoclay based on montmorillonite is a layered mineral deposit of smectite family extracted from volcanic ash deposit in brine seas [9]. Individual clay particle has high aspect ratio with surface area of around 600 nanometers and thickness of only 1 to few nanometers. Crystal structure of silicate layer consists of central octahedral sheet of alumina or magnesia fused to two external silica tetrahedron sheets. Charge on the surface is known as cation exchange capacity
(CEC) expressed in meq/100 g. Leuteritz et al. compared properties of nanocomposites of four different natural clays (montmorillonite) and layered silicates with different cation exchange capacity (CEC). The highest impact strength properties were observed for the nano composites with the highest CEC [10].

Silicate clay layers have polar hydroxyl groups, which make them incompatible with nonpolar olefins. So in natural form, clay can disperse only in hydrophilic polymers like Poly(ethylene oxide) and Poly(vinyl alcohol). In order to render the surface more organophilic, cations of surface have to be replaced by cationic surfactants [11-14]. Completely exfoliated clay platelet-polymer composites are difficult to produce since the two materials have widely differing natures, clay having a rigid structure with a hydrophilic oxide surface versus flexible hydrophobic organic polymers, which prevents dispersing of them together. Thermodynamically, the strongly hydrophilic clay and hydrophobic polymers lack attractive enthalpic forces to overcome the electrostatic force which pulls sheets together. The free energy of mixing between clay and polymer is positive, and so the mixing is not thermodynamically favorable. 
TABLE 1: Nylon 6 sample details.

\begin{tabular}{lccc}
\hline Sample & Clay composition & Thickness $(\mu)$ & Yellowness $(b)$ \\
\hline CN6F & $0 \%$ & 860 & 0.16 \\
N6CF2 & $2 \%$ & 600 & 1 \\
N6CF5 & $5 \%$ & 760 & 3 \\
N6CF10 & $10 \%$ & 1520 & 5 \\
\hline
\end{tabular}

In melt compounded system, to achieve intercalation or exfoliation of the clay by a polymer requires inclusion of a "compatibilizer" to create favorable enthalpic interactions and to lower surface free energy [15-18]. Such agents could be tailored to have an enthalpic attraction with the clay surface as well as with the polymer chains, mitigating the poor thermodynamics of mixing. Thus, making production of a well-dispersed exfoliated clay-polymer nanocomposite with strong interfacial adhesion possible.

Melt blended nylon 6-organo-modified clay-based nanocomposites have been produced and reported before $[4,19$, $20]$. Detailed illustration of different crystal phases in nylon6 and nylon-6 composites are available in the literature [21]. It is known that clay additives can be exfoliated with the filler content less than $10 \%$. Nanoclay additive is known to favor formation of $\gamma$-crystals (pseudohexagonal unit cell). Most of the earlier studies for the nylon 6-nanoclay composites were focused on the molded composite bars and its mechanical properties. Xie et al. have reported structure and mechanical properties of injection-molded nylon-6/montmorillonite nanocomposites [22]. In our previous studies, we have reported detailed morphology studies on the influence of nanoclay on the structure and properties of melt blown webs and spun bond polypropylene webs [23-25]. However, to date, influence of nanoclay additives on the morphology and properties of nylon-6-blown films has not been studied or reported in detail.

In this study, for the first time, we report results from a detailed study on the influence of nanoclay additive on the structure, morphology, and mechanical properties of nylon6-blown films with different weight percentage of nanoclaybased additives. Even though it is difficult to disperse in polymer matrix, we have used natural nanoclay because clay in natural form is approved by the U.S. Food and Drug Administration (FDA) for food contact and end product does not contain any surface cationic surfactants. We have investigated the morphology and mechanical properties of nylon6-blown films with different percentage of Cloisite $\mathrm{Na}^{+}$ additives which were produced at a commercial blown film pilot line. So the results are directly applicable to industry.

\section{Experimental}

2.1. Materials. Melt compounding of nylon 6 and Closite $\mathrm{Na}^{+}$was done on a counter rotating twin screw extruder $(L / D=28: 1 \mathrm{~mm})$. The extrusion zone temperature were in the range of 238 to $243^{\circ} \mathrm{C}$ to produce concentrates containing clay $\mathrm{wt} \%$ as shown in Table 1 . The concentrates were used to produce blown films on the pilot line at Techmer PM. Clay composition and properties of the films received are included in Table 1. Most of the film samples were in the thickness range of 600 to 1520 microns. Slightly thicker films were produced for concentrate with $10 \mathrm{wt} \%$ clay to produce uniform film. Extent of color change in film sample Yellowness $(b)$ due to incorporation of nanoclay additives was determined using Miniscan XE hunter colorimeter.

\subsection{Testing and Characterization}

2.2.1. Wide-Angle X-Ray Diffraction (WAXD). WAXD of samples was carried out using a Phillips X Pert Pro Xray Diffraction System in continuous scan mode. Equatorial scans were obtained from $2 \theta=2^{\circ}$ to $30^{\circ}$ in steps of $0.01^{\circ}$ and a dwell time of 4 seconds, operated at $45 \mathrm{kV}$ and $40 \mathrm{~mA}$.

Crystal size $(t)$ was calculated using the Scherrer equation [26] as shown in (1), from the measured full width at half maximum (FWHM) intensity of reflection peaks in the equatorial scans. Scherrer equation is given as

$$
t=\frac{0.9 \lambda}{\beta \cos \theta},
$$

where $\lambda$ is the wavelength in $\AA$ and $\beta$ is the measured FWHM (full width at half maximum) intensity of (011) reflection peaks; where, $\beta$ integral breadth of reflection located at $2 \theta$. The (011) peak was assumed to be Gaussian and FWHM was corrected for the instrumental broadening as per (2):

$$
\beta=\sqrt{\beta_{\text {observed }}-\beta_{\text {instrumental }}},
$$

where $\beta_{\text {observed }}$ is the observed FWHM and $\beta_{\text {instrumental }}$ is the instrumental broadening factor.

2.2.2. Differential Scanning Calorimeter (DSC). Thermal analysis was carried out using the DSC. Samples were heated from $40^{\circ} \mathrm{C}$ to $240^{\circ} \mathrm{C}$ at a heating rate of $10^{\circ} \mathrm{C} / \mathrm{min}$ in the $\mathrm{N}_{2}$ atmosphere, held at $240^{\circ} \mathrm{C}$ for 10 minute to ensure complete melting of all the crystals, and then cooled to room temperature at rate of $-10^{\circ} \mathrm{C} / \mathrm{min}$.

2.2.3. Crystallization Kinetics. Influence on nanoclay on the melting and crystallization behavior was investigated using isothermal and nonisothermal crystallization kinetics. For isothermal crystallization kinetics, samples of approximately $6 \pm 0.5 \mathrm{mg}$ were heated from $40^{\circ} \mathrm{C}$ to $240^{\circ} \mathrm{C} / \mathrm{min}$, held at $240^{\circ} \mathrm{C}$ for $10 \mathrm{~min}$ to erase process history, cooled from $240^{\circ} \mathrm{C}$ to $160^{\circ} \mathrm{C}$ at a cooling rate of $-80^{\circ} \mathrm{C}$, and then crystallization kinetics data were collected at $160^{\circ} \mathrm{C}$ for $45 \mathrm{~min}$. The relative crystallinity at different crystallization time $X(t)$ was obtained from the ratio of the area of the exotherm up to time $t$ divided by the total exotherm given by (3), where $Q_{t}$ and $Q_{\infty}$ are the heat generated at time $t$ and infinite time, respectively, and $d h / d t$ is the heat flow rate [27]. Observed increase in crystallinity with time $X(t)$ was estimated by Avrami Equation (4) which represents unimpeded spherical crystal growth [28]. Equation (4) can be re arranged as (5),

$$
X(t)=\frac{Q_{t}}{Q_{\infty}}=\frac{\int_{0}^{t}(d h / d t) d t}{\int_{0}^{\infty}(d h / d t) d t},
$$




$$
\begin{gathered}
1-X(t)=\exp \left(-K t^{n}\right) \\
\log [-\ln (1-X(t))]=\log K+n \log t
\end{gathered}
$$

From the plot of $\log [-\ln (1-X(t))]$ versus $\log (t)$, Avrami parameters $n$ (slope) and $K(y$-intercept) were determined; where, $n$ is the Avrami exponent, $K$ is the rate constant which describes the crystallization rate and $t$ is the crystallization time [29]. For spherulitic form of crystal growth, $n$ values are often obtained between 1 and 4 [30].

For nonisothermal crystallization kinetics, samples were initially held at $40^{\circ} \mathrm{C}$ for $5 \mathrm{~min}$, heated from 40 to $250^{\circ} \mathrm{C}$, about $20^{\circ} \mathrm{C}$ above the melting temperature of nylon 6 , at a rate of $10^{\circ} \mathrm{C} / \mathrm{min}$. The samples were kept at $250^{\circ} \mathrm{C}$ for 5 minute to eliminate all the processing history and cooled back to room temperature at cooling rates of 5, 10, 20, 50, 65, and $80^{\circ} \mathrm{C} / \mathrm{min}$ to $40^{\circ} \mathrm{C}$. Variation in crystallization behavior and nature of exotherm for different sample was studied.

2.2.4. Thermo Gravimetric Analysis (TGA). TGA of samples was carried out using a METTLER TGA SDTA 851. Samples were heated from room temperature to $500^{\circ} \mathrm{C}$ in nitrogen atmosphere. Difference in decomposition, thermal transition and ash content are analyzed.

2.2.5. Transmission Electron Microscopy (TEM). TEM images of neat nanoclay were taken by depositing clay powder on a standard 400 grid copper mesh. Sections less than $60 \mathrm{~nm}$ thickness were cut from nylon 6 films with clay using RMC Power tome CRX microtome with diamond knife. TEM image was obtained from Hitachi $\mathrm{H}-800$ operated at $200 \mathrm{kV}$.

2.2.6. Scanning Electron Microscopy (SEM). SEM images of surface and cross-section of the samples were taken using a Leo 1525 Field emission Gun. In order to avoid charging problems, samples were coated with gold for 10 seconds in argon environment using SPI sputter coater.

2.2.7. Atomic Force Microscopy (AFM). AFM experiments were performed in tapping mode using the Digital Instruments scanning probe microscope to measure surface topography. The AFM tips were standard Veeco 0.01-0.025 Ohm$\mathrm{cm}$ Antimony $(n)$ doped Si tips with a resonance of around $289-334 \mathrm{kHz}$, with a spring constant $k-20-80 \mathrm{~N} / \mathrm{m}$. The cantilever thickness $t: 3.5-4.5 \mu \mathrm{m}$, length $l: 110-140 \mu \mathrm{m}$, and width $w$ : 25-35 $\mu \mathrm{m}$. From the height image, roughness and section analysis was performed. Phase image can also be used to map stiffness variation of sample surface. The phase shift depends on the time-averaged surface stiffness $\langle s\rangle$ and contact radius $r_{c}$, the cantilever properties $Q$ (quality factor) and $k$ (spring constant) and the effective modulus $E^{*}$ as per (6) $[31]$ :

$$
\Delta \Phi \approx\langle s\rangle\left(\frac{Q}{k}\right)=\varepsilon\left\langle r_{c}\right\rangle E^{*} \frac{Q}{k} .
$$

This equation shows that phase image could be used for stiffness mapping of sample surface, such that in phase image, stiffer region has a higher positive phase shift and hence appears brighter [32].
2.2.8. Polarized Light Microscopy. Samples listed in Table 1 were melted and allowed to crystallize between glass slides. Small pieces of films were placed in between a glass slide and cover slip. Samples were isothermally melted at $270^{\circ} \mathrm{C}$ using a hot press and kept in molten state for $10 \mathrm{~min}$ to ensure complete melting. The hot press was then switched off and the samples were allowed to cool on the heated plate of the hot press. Average thickness of the crystallized film was less than $200 \mu \mathrm{m}$. Spherulite images were analyzed using Olympus BX51 polarized optical microscope. Maximum diameter of spherulite was determined from average of $n=$ 30 spherulite measurements.

2.2.9. Mechanical Properties Testing. Tensile properties were determined using the United Tensile Tester (as recommended in ASTM standard D3822-07). Film samples of $25 \mathrm{~mm}$ width were clamped at a gauge length of $75 \mathrm{~mm}$ and stretched to break at a uniform strain rate of $30 \mathrm{~mm} / \mathrm{min}$. Tear strength was conducted using the Elmendorf tear tester (as recommended in ASTM standard D5734-95). Burst strength was tested using the B F Perkins, Mullen burst tester (as recommended in ASTM standard D3786-87).

2.2.10. Nanoindentation Testing. Nanoindentation technique was used to investigate the mechanical properties of nanoclay incorporated nylon 6 films. Nanoindentation experiment was carried out using Nanoindenter X.P MTS is tester with Berkovich hp tip, $2 \mathrm{~nm}$ for continuous stiffness at strain rates of $0.02,0.05,0.1,0.2 \mathrm{sec}^{-1}$. Each indent was separated by $150 \mu \mathrm{m}$ to avoid overlapping of plastic deformation between neighboring indents. To learn more about nano-indentation, readers are encouraged to refer to the paper by Oliver and Pharr [33]. Detailed experimental steps and scientific principles of nanoindentation are included in supplementary information.

2.2.11. Contact Angle Measurement. Influence of nanoclay additive in the surface wettability of nylon 6 films was determined by contact angle measurement using sessile drop technique. Decrease in contact angle indicates the extent of liquid drop spreading on the solid surface. The contact angles of sessile drops of water on the nylon 6 films were measured using Easy drop device from KRUSS. The water was dispensed from the syringe at a constant rate of $5 \mu \mathrm{L} / \mathrm{min}$. The contact angles were measured on the digitized optical image of the drop on both the edges using the software. Average of 20 readings is taken as contact angle data for each of the blown film sample. Scientific principles of contact angle analysis are included in supplementary information.

\section{Results and Discussion}

WAXD scans of films with different weight $\%$ of nanoclay additive are included in Figure 1. WAXD scan of neat clay is shown in Figure 1(a). Diffraction peak corresponding to (100) plane of neat clay (occurs at $2 \theta$ of $6.07^{\circ}$ ) increased for sample with increase in wt $\%$ of additive in film. This peak intensity corresponding to clay decreases with intercalation/exfoliation and completely disappears for fully exfoliated samples. Film N6CF2 (with 2\% clay) has the lowest 


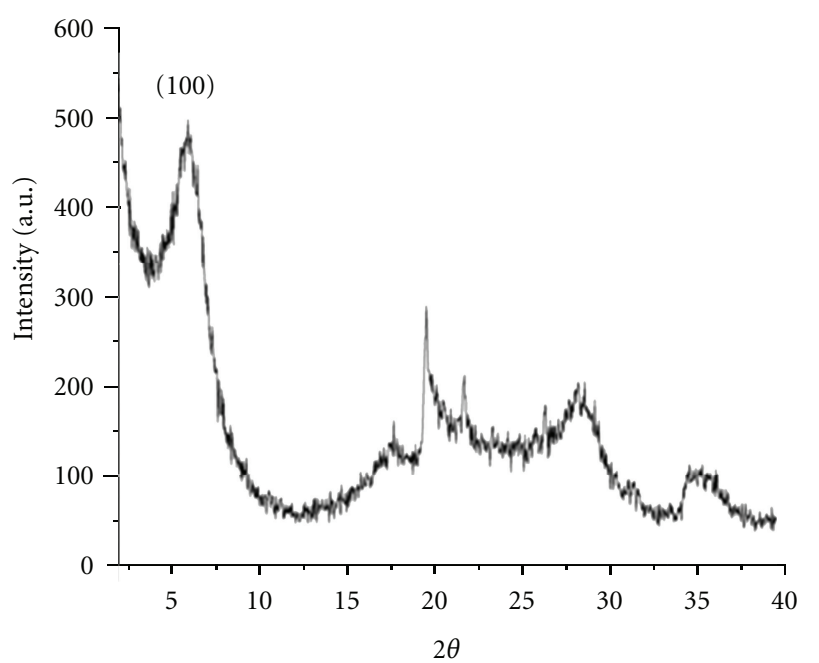

— Natural nano clay

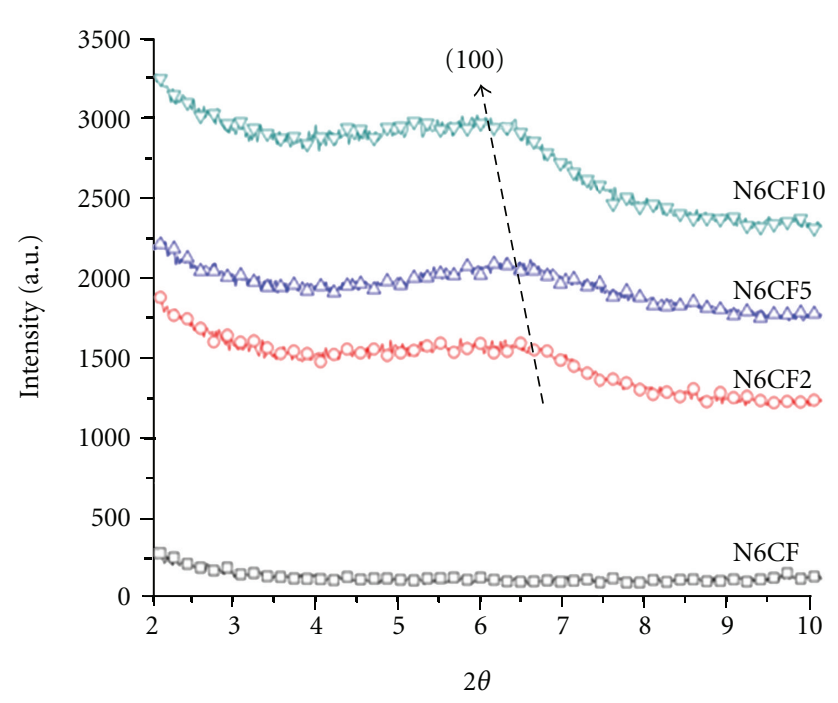

(b)

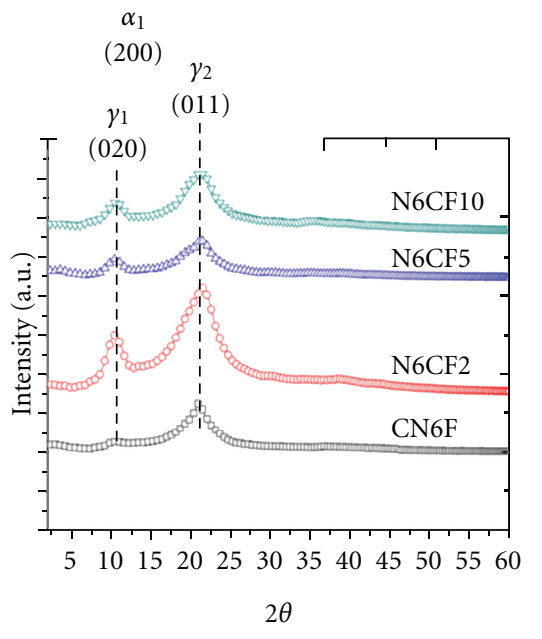

(c)

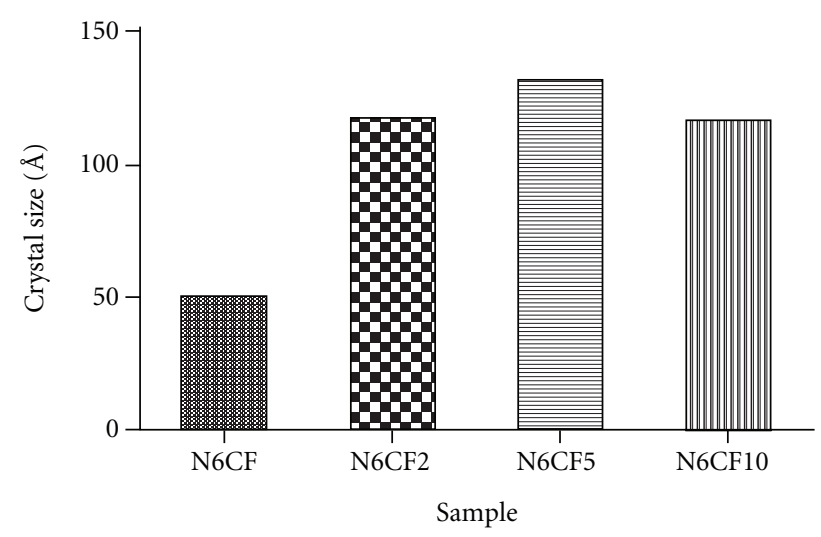

(d)

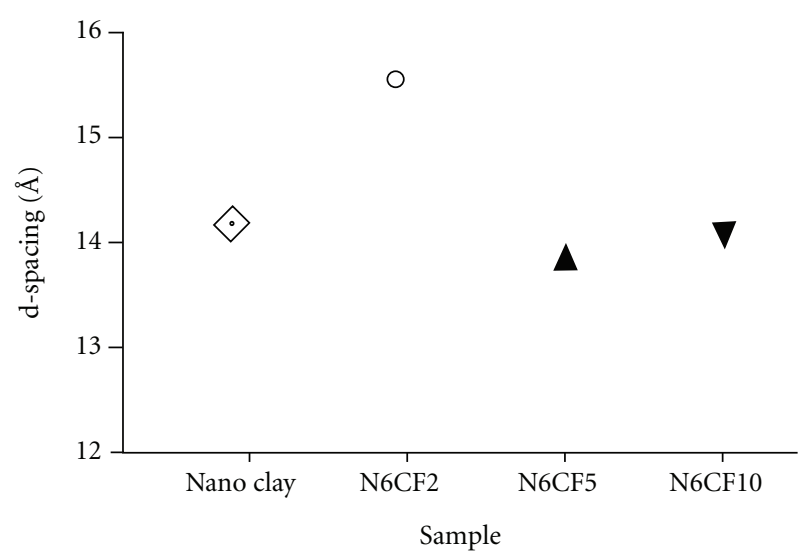

(e)

FIGURE 1: WAXD scans of (a) neat nanoclay (b) peak corresponding to (100) plane of neat nanoclay, (c) film samples, (d) crystal size, (e) results of $d$-spacing of from (100) peak position. (Color figure can be viewed in the online issue). 


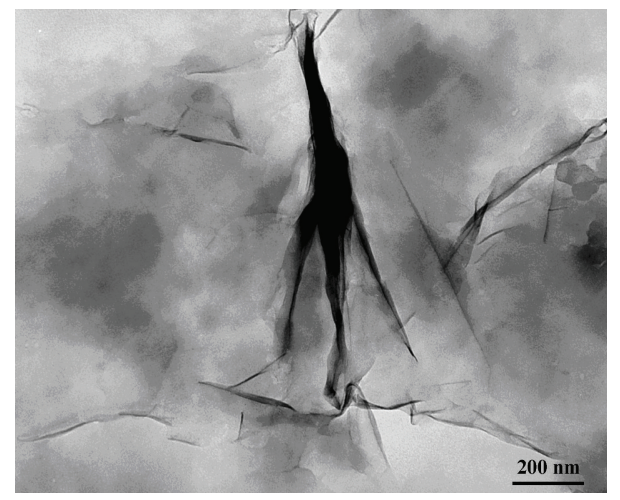

Figure 2: Transmission electron microscopy image of neat nanoclay.

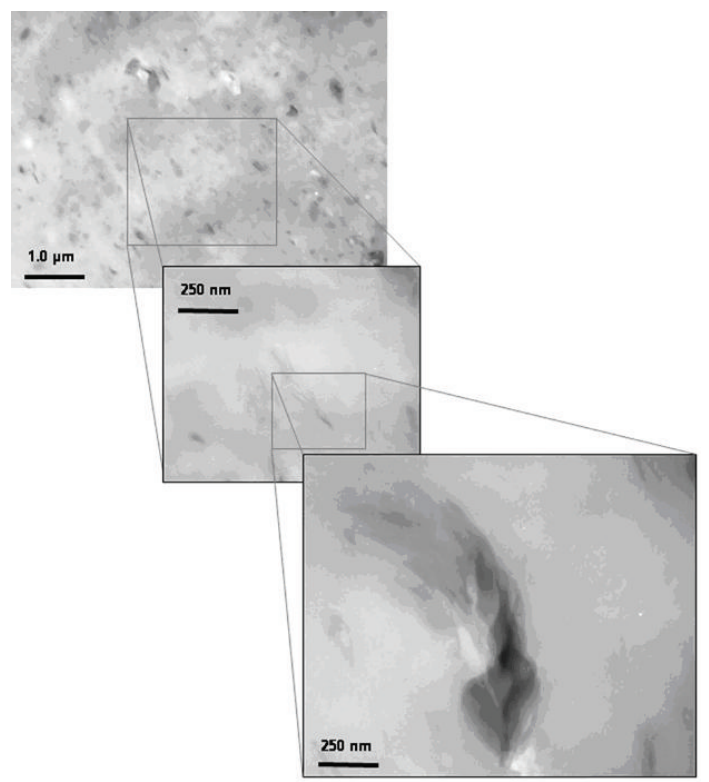

Figure 3: TEM image of nylon-6 film with $2 \mathrm{wt} \%$ nanoclay.

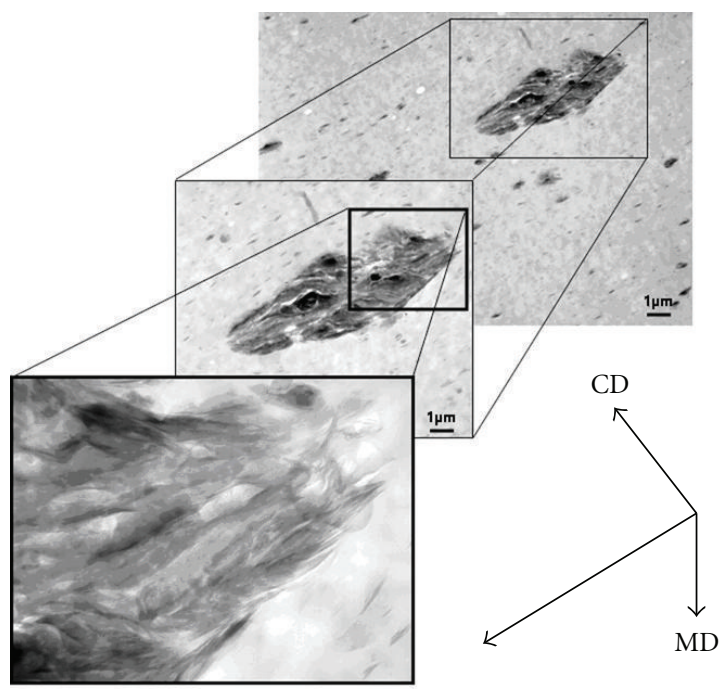

FIGURE 4: TEM image of nylon-6 film with $5 \mathrm{wt} \%$ nanoclay.

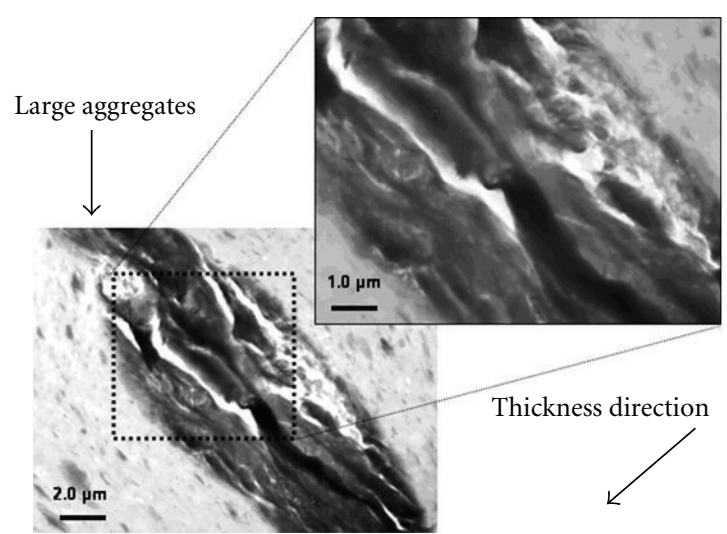

Figure 5: TEM image of nylon-6 film with $10 \mathrm{wt} \%$ nanoclay.

peak intensity corresponding to (100) plane of nanoclay (Figure 1(b)).

The WAXD scans of the film composites are shown in Figure 1(c). The $\alpha$-phase (monoclinic unit cell) and $\gamma$-phase (pseudohexagonal unit cell) of nylon 6 are assigned as reported in literatures [34].

Diffraction peak at $10.7^{\circ}$ correspond to $\gamma$-phase (pseudohexagonal unit cell) is defined as $\gamma_{1}$. The center peak at $2 \theta$ of $20^{\circ}$ is superposition of $\alpha_{1}$ corresponding to (200) plane at $2 \theta$ of $20^{\circ}, \gamma_{2}(011)$ plane at $2 \theta$ of $21.3^{\circ}$, and $\alpha_{2}$ corresponding to (202) plane at $2 \theta$ of $23.7^{\circ}$, respectively. Compared to CN6F for all films with additives, intensity and area of peak corresponding to $\gamma_{1}$-crystalline form increased with additives. This indicated the increase in $\gamma$-phase for films with additives. This is in agreement with earlier findings [4].

Results of crystal size $(t)$ calculated from the Scherrer equation is shown in Figure 1(d). Crystal sizes are higher for all the samples with additives. Results of d-spacing of clay platelets are shown in Figure 1(e). Only for N6CF2, $d$ spacing increases compared to neat clay but for the N6CF5 and N6CF10, $d$-spacing is lower than the neat nanoclay platelets which might be due to presence of large tactoids and agglomerates.

Crystallinity wt\% was not estimated from the WAXD scans due to complications and possible errors involved in peak fitting. One of the complications is the center peak consisting of superimposition of reflections from crystalline and amorphous portions. 2D WAXS pinhole patterns of films (Figure S1, supplementary information, available at doi: $10.1155 / 2012 / 959035)$ do not show significant change in orientation for any samples.

TEM image of neat nanoclay is shown in Figure 2. Dark shady lines in the image represent the cross-section of layered clay platelets, each of thickness less than $10 \AA$. TEM images of film sample with 2,5 and $10 \mathrm{wt} \%$ nanoclay additive are included in Figures 3, 4, and 5, respectively. Images revealed clay platelets of thickness less than $5 \mathrm{~nm}$ uniformly dispersed in sample. Sample N6CF2 (Figure 3) shows better exfoliation of clay in the matrix compared to N6CF5 and N6CF10. Good dispersion of additive is due to the polar nature of nylon6 and hydrogen bond formation between clay and nylon- 6 chains [35]. 


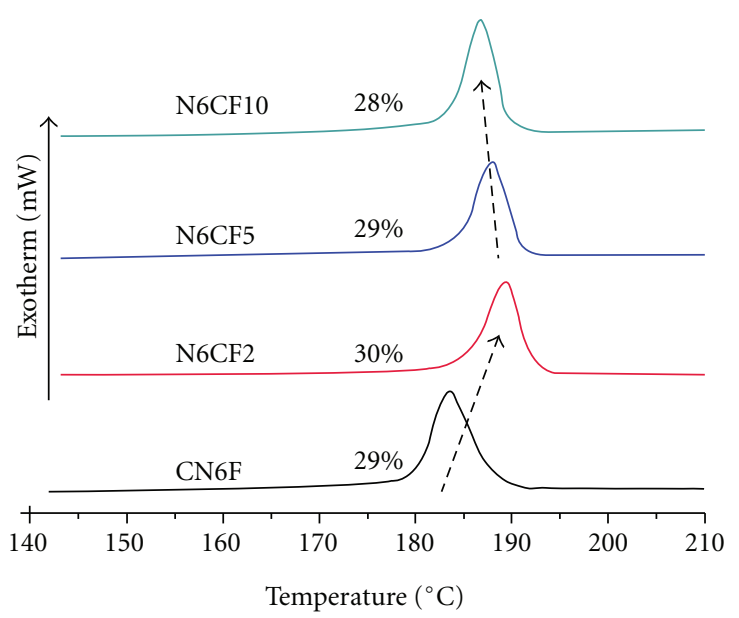

(a)

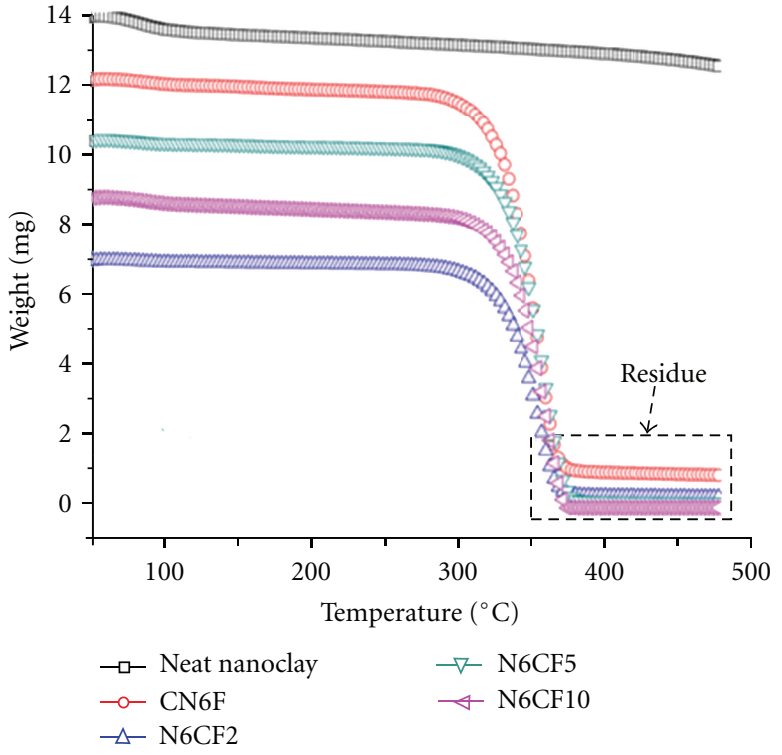

(b)

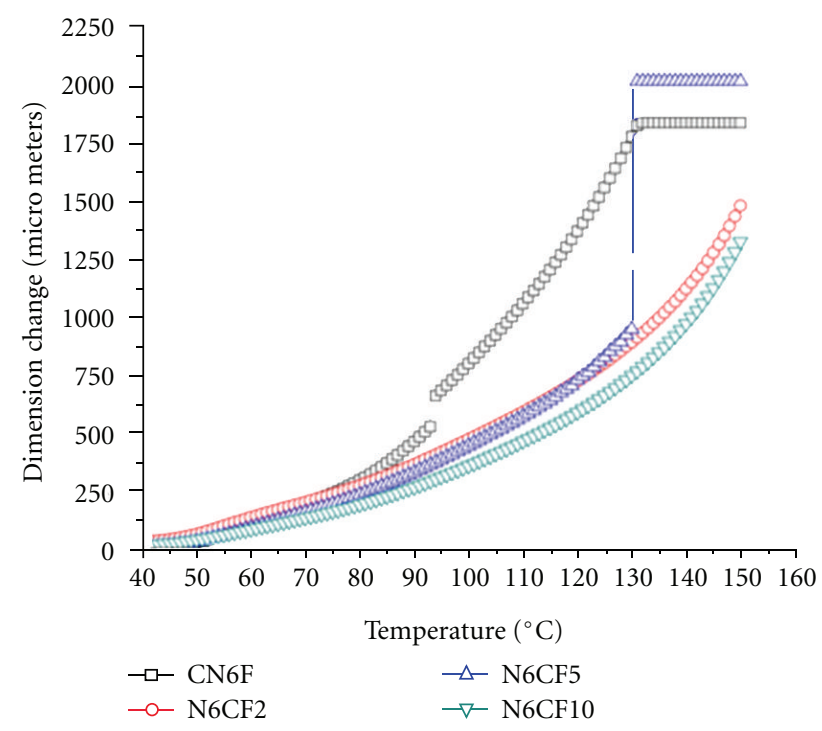

(c)

Figure 6: (a) DSC cooling segment scans of samples, (b) TGA scans of film samples, (c) TMA scans of samples. (Color figure can be viewed in the online issue).

In the case of N6CF5 (film sample with $5 \mathrm{wt} \%$ additive), (Figure 4), slightly large well-dispersed tactoids were observed. Low-magnification micrographs also revealed better dispersion of clay platelets through the samples along the direction of melt flow. At high magnification, image shows significant intercalation of polymer chains within the clay galleries of individual tactoids. Image also reveals the influence of processing conditions on the additive orientation and distribution of particle in the sample. Overall sample had clay platelets oriented along the machine direction of film. The platelet surfaces were oriented parallel to the thickness direction. Similar orientation and distribution of platelets has been reported in earlier studies for injection-molded composites $[7,36,37]$, which reconfirms the influence of processing conditions on additive orientation and distribution.

In the case of sample N6CF10 with high-weight percentage clay, highly aggregated and intercalated morphology is obtained (Figure 5). The agglomerates have enough void in between the platelets. Delamination of clay platelets with large clay agglomerates caused microvoids in the samples. Most of the voids nucleated between the clay layers because, electrostatic interaction between the clay platelets is weak compared to strong interaction between the clay platelets and nylon 6 matrix [38].

3.1. Thermal Analysis. Results of DSC cooling segments are included in Figure 6(a) and Table 2. All the films with 


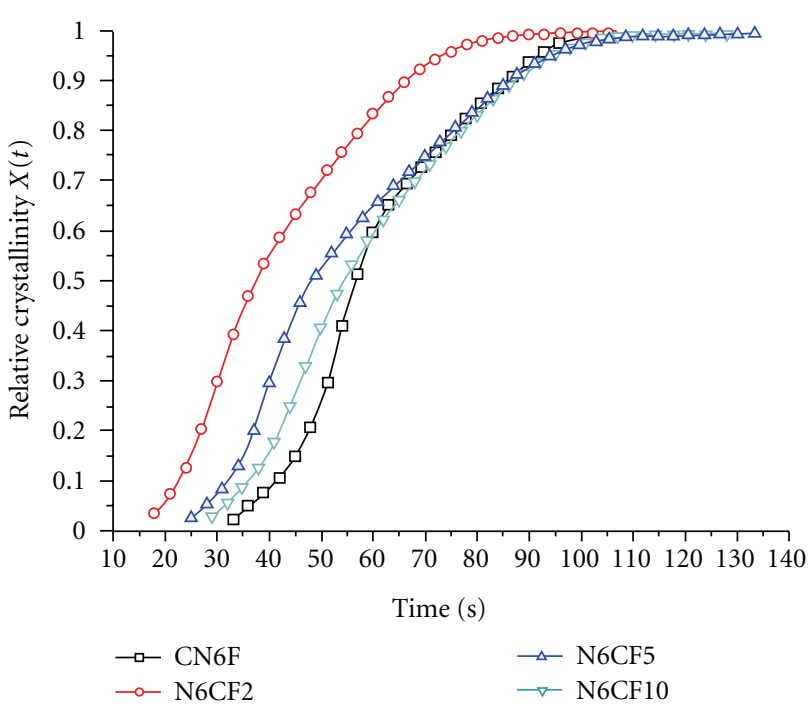

(a)

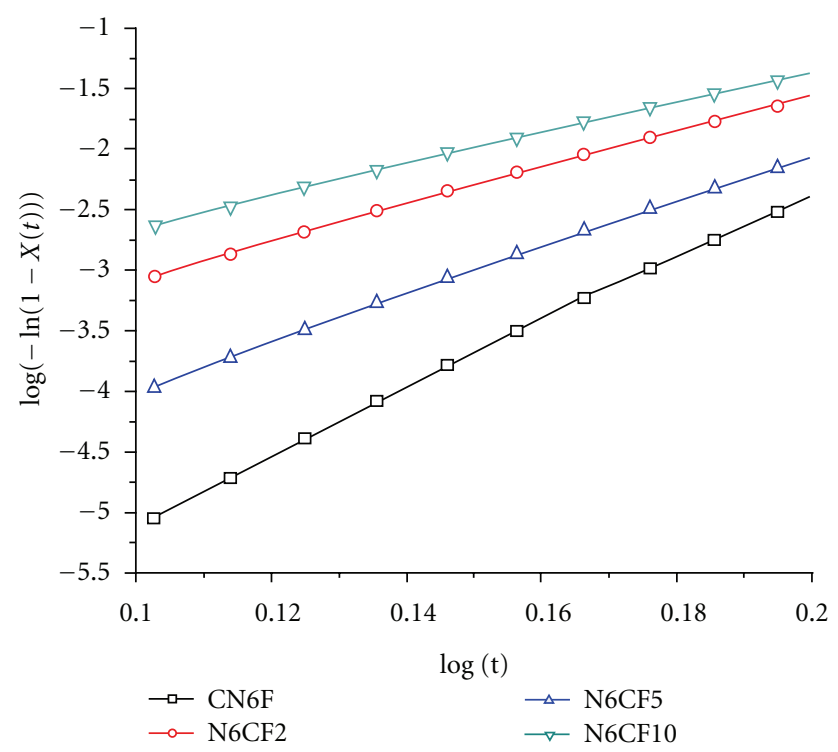

(b)

Figure 7: (a) Relative crystallinity for film samples, (b) Avrami plots $\log [-\ln (1-X(t))]$ versus $\log (t)$ for different film samples (color figure can be viewed in the online issue).

nanoadditives show higher peak crystallization temperatures than that of $\mathrm{CN} 6 \mathrm{~F}$ which indicates sufficient nucleating effect of additives. Also, there is some shift in peak melting temperature which indicates differences in extent of nucleation between different add on levels. Also compared to CN6F, films with additives have narrow melting range which indicates narrow crystal side distribution. Among all the samples, N6CF2 shows the highest increment in the onset and peak temperature which indicates significant dispersion of the clay platelets to influence properties at nanoscale.

Influence of clay additive on thermal stability has been reported before. Nanoclay platelets are known to act as blocking agents and reduce surface oxidation of released condensed phase species [39]. Lower heat and $\mathrm{CO}_{2}$ are
TABLe 2: Nylon 6 film DSC results.

\begin{tabular}{lcccc}
\hline Sample & CN6F & N6CF2 & N6CF5 & N6CF10 \\
\hline Clay $($ wt\% $)$ & 0 & 2 & 5 & 10 \\
Onset & 191 & 194 & 192 & 191 \\
Peak & 183 & 189 & 188 & 187 \\
Endpoint & 181 & 169 & 176 & 179 \\
Crystallinity wt\% & 29 & 30 & 29 & 28 \\
Ash\% by TGA & 0 & 1.5 & 4.5 & 7.7 \\
Dimension change $(\mu \mathrm{m})$ at & 750 & 475 & 450 & 270 \\
$100^{\circ} \mathrm{C}$ by TMA & & & & \\
\hline
\end{tabular}

released for sample reinforced with clay. TGA scans of neat Closite $\mathrm{Na}^{+}$and nylon-6 nanocomposite films (Figure 6(b)) showed slight shift in thermal decomposition temperature for films with 2 and $10 \mathrm{wt} \%$ clay additives. $5 \mathrm{wt} \%$ loss in temperature range of $90^{\circ} \mathrm{C}$ to $100^{\circ} \mathrm{C}$ for neat nanoclay is due to the evaporation of moisture which is in agreement with the moisture content reported by Southern Clay Products [40]. There is slight delay in the thermal transition for films with additives. This delay in thermal transition also reported in earlier studies is due to char formation [41]. Char acts as insulator and protects the polymer chain from further degradation. Results of ash content at $500^{\circ} \mathrm{C}$ at the end of the experiment included in Table 4 reconfirmed the presence of clay as used in the sample. Ash residue increased with weight $\%$ of clays $(2 \%<5 \%<10 \%)$ in films.

It is well known that there exists strong hydrogen bond between nylon polymer chains and clay platelets due to polar nature of nylon 6 chains [42]. The strong interaction between the polymer matrix and clay platelets acts as crosslink points and further reinforces the molecular network. These physical crosslink's and reinforcement make stable molecular network and restrict the motion of molecules.

TMA scans of samples (Figure 6(c)) show significant difference in dimensional change for nanocomposites. Thermal transition in the sample at $100^{\circ} \mathrm{C}$ is shown in Table 2 . Thermal expansion for $\mathrm{CN} 6 \mathrm{~F}$ initiates at $92^{\circ} \mathrm{C}$, whereas expansion for N6CF5 occurs at $130^{\circ} \mathrm{C}$. Films N6CF2 and N6CF10 do not show any swift expansion with temperature. This shift in thermal transition for nanocomposites is due to restricted thermal motion of chains due to presence of nanoclay. Also films with additives showed elongational behavior. In earlier studies, it has been shown that $\gamma$ crystalline forms acquire higher draw capability of nylon 6 in the temperature range of 110 to $180^{\circ} \mathrm{C}$ [43], and increased $\gamma$-crystalline forms for films with additives are evident from the WAXD results (Figure $1(\mathrm{c})$ ).

3.2. Isothermal Crystallization Kinetics. Relative crystallinity at different time is shown in Figure 7(a). Crystallization occurs in two stages: primary crystallization via nucleation and secondary crystallization which involve growth and perfection of nucleates in lateral direction [44]. In the case of N6CF2, well-dispersed clay platelets act as nucleating sites and facilitate crystallization. It is evident that N6CF2 achieves saturation before CN6F. Whereas for N6CF5 and 
TABLE 3: Crystallization parameters for different film samples.

\begin{tabular}{lcccc}
\hline Sample & CN6F & N6CF2 & N6CF5 & N6CF10 \\
\hline$n$ & 4 & 2.4 & 3.2 & 2.8 \\
$K$ & 1.2 & 1.5 & 1.9 & 1.2 \\
$t 1 / 2(\mathrm{~min})$ & 1.0 & 0.6 & 0.8 & 0.8 \\
$t_{\max }(\mathrm{min})$ & 1.9 & 1.1 & 2.1 & 2.1 \\
$G(1 / \mathrm{min})$-exp & 1.1 & 1.6 & 1.2 & 1.2 \\
$G(1 / \mathrm{min})-$ theory & 1.1 & 1.4 & 1.4 & 1.2 \\
$H_{f}(\mathrm{~J} / \mathrm{g})$ & 89 & 65 & 72 & 67 \\
\hline
\end{tabular}

TABLE 4: Tensile strength results of nylon-6 nanocomposite films.

\begin{tabular}{|c|c|c|c|}
\hline \multicolumn{2}{|c|}{ Sample Peak force (gms) } & \multirow{2}{*}{$\begin{array}{c}\text { Peak elongation }(\%) \\
323\end{array}$} & \multirow{2}{*}{$\frac{\text { Modulus }(\mathrm{GPa})}{2.0}$} \\
\hline CN6F & 6155 & & \\
\hline N6CF2 & 7879 & 230 & 2.4 \\
\hline N6CF5 & 8972 & 16 & 2.9 \\
\hline N6CF10 & 7539 & 14 & 2.8 \\
\hline
\end{tabular}

N6CF10, even though additives act as nucleating agent initially in primary crystallization, during the secondary crystallization, the transition and saturation are achieved slower than the CN6F. The large nucleation sites and clay tactoids hinder the polymer chain diffusion to the growing spherulites.

Results of Avrami plots $\log [-\ln (1-X(t))]$ versus $\log (t)$ for different film samples is shown in Figure 7(b). From the slope and $y$-intercept, Avrami parameters $n$ and rate constant $K$ were determined. Results of Avrami parameters, half time and rate of crystallization are presented in Table 3. The parameter " $n$ " varies within the range 3 to 4 which is due to spherulitic form of crystal growth [45]. The spherulite form of crystal growth is reconfirmed by the polarized optical micrographs (Figure 11). Value of $n$ decreases slightly for the sample with additives which indicates decrease in spherulite dimension. Rate constant $K$ which indicates rate of crystallization is higher for N6CF2 and N6CF5, but for N6CF10 rate drops and is equivalent to that of CN6F. This indicates that for N6CF10, nucleation is heterogeneous and large nucleation sides hinder the rate of crystallization. Similar observations were reported for nylon 66/MWNT composites [46].

3.3. Nonisothermal Crystallization Kinetics. All the graphs of nonisothermal crystallization kinetics are included in supplementary information Figures S2 to S5 and Table S1. At lower cooling rate, crystallization starts at higher temperature because there is more time available to overcome nucleation barrier. With increase in cooling rate, the peak crystallization temperature shifts to lower temperature [47]. Clay additive significantly influences the nonisothermal crystallization kinetics. Presence of clay leads to slight increase in crystallization temperature for the films.

3.4. Mechanical Properties. Results of tensile test are shown in Figure 8 and Table 4. Peak force is higher for the sample

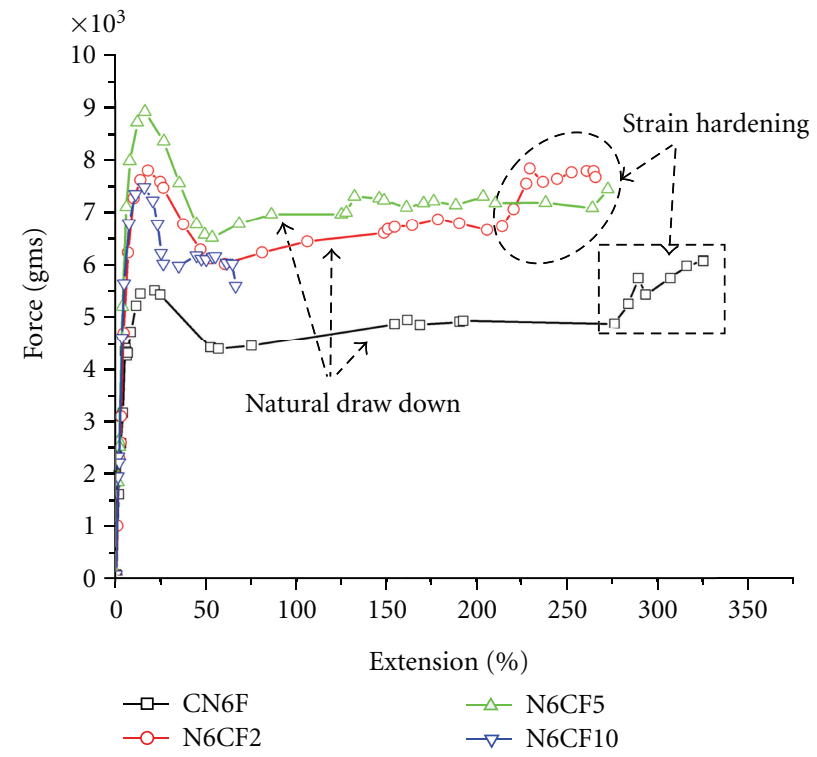

FIGURE 8: Tensile strength results of nylon-6 nanocomposite films (color figure can be viewed in the online issue).

TABLE 5: Nylon 6 film TGA, tear strength and burst strength results.

\begin{tabular}{lccc}
\hline Sample & $\begin{array}{c}\text { Tear strength } \\
(\mathrm{cN})\end{array}$ & $\begin{array}{c}\text { Burst strength } \\
(\mathrm{Mpa})\end{array}$ & $\begin{array}{c}\text { Average vertical } \\
\text { distance }(\mathrm{nm})\end{array}$ \\
\hline CN6F & 95 & 0.26 & 4.7 \\
N6CF2 & 88 & 0.31 & 8.0 \\
N6CF5 & 76 & 0.35 & 9.3 \\
N6CF10 & 73 & 0.21 & 14.8 \\
\hline
\end{tabular}

with clay additives. Tensile profile of the films show multiple segments peak force, yield, natural drawdown, and strain hardening. N6CF2 and N6CF5 show strain hardening after the natural drawdown before failure like the CN6F (control). The natural drawdown indicates extent of transfer of neck boundary along the length of sample. Comparing between the $\mathrm{CN6F}$ and sample with clay, it is clear that level of draw down decreases for N6CF2 and N6CF5. After complete draw down/neck transfer, samples CN6F, N6CF2, and N6CF5 show upturn in the stress. This region is known as strain hardening and results from additional molecular orientation in the films until failure. N6CF2 shows second draw down after strain hardening. Natural draw down and strain hardening indicates that CN6F, N6CF2, and N6CF5 are tough and hard. The sample N6CF10 (with $10 \mathrm{wt} \%$ ) fails without any natural drawdown and fails at low percentage strain. N6CF10 shows ductile draw of about $45 \%$ and then it shows hard and brittle failure. For N6CF10, after yield segment, there is a short drawdown, chains are unable to slip further. This indicates that sample shows increased hardness and toughening effect till $5 \mathrm{wt} \%$ clay additive and at $10 \mathrm{wt} \%$ becomes harder and brittle.

Films burst strength and cross-direction (CD) tear strength are shown in Table 5. Improved burst strength and increased toughness of film are due to combined effect of 


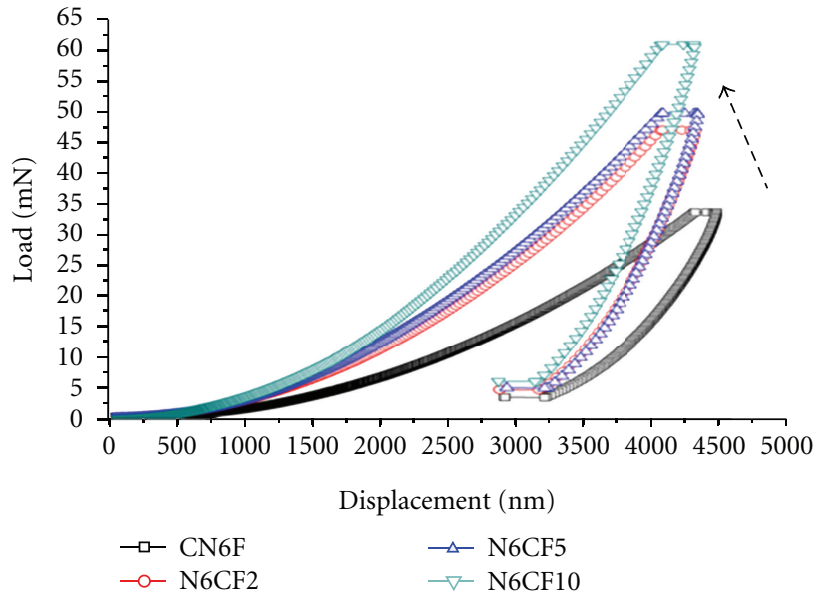

(a)

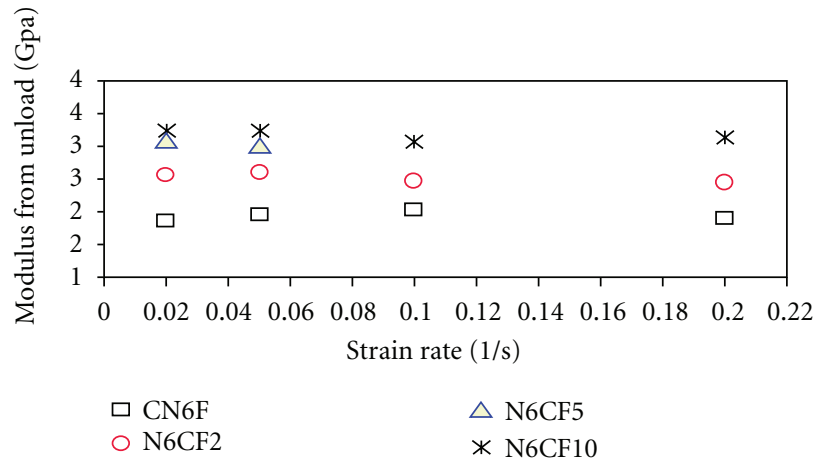

(b)

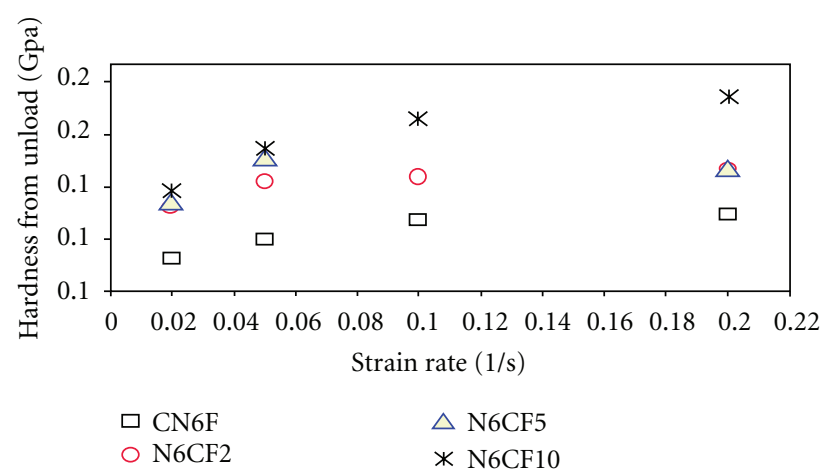

(c)

Figure 9: Results of nanoindentation, (a) load-hold-unloading profiles, (b) surface modulus, and (c) hardness for sample (color figure can be viewed in the online issue).

reinforcement in amorphous region and nonhomogeneous distribution of high modulus ( $400 \mathrm{Gpa}$ ) of clay platelets. Tear strength does not show any increase with clay loading. This is expected since in a tear strength test, test is initiated on sample which is torn half of its test width and stress is highly concentrated and applied at high rate compared to tensile test. At this high rate, voids between the clay platelets (as shown in the TEM micrograph Figure 5) act as weak spots and facilitate easy propagation of tear.

3.5. Nanoindentation. Results of Nanoindentation tests are shown in Figures 9(a), 9(b), and 9(c). Details of the experimental steps, scientific concepts of Nanoindentation are included in supplementalry information. In the Load unload curve (Figure 9(a)), overall load for films with additives is higher than that of $\mathrm{CN} 6 \mathrm{~F}$ as addition of high modulus (400 Gpa) clay platelet increases the stiffness of material.

The initial slope of unloading curve indicates the unloading stiffness $(d p / d h)$ together with contact area $(A)$ [33]. The initial slope of unloading curve (Figure 9(a)) increases with concentration of clay. Modulus is determined by the initial slope of the unloading curve (details are included in supplementary information). Maximum depth of indentation decreases with the increase in clay concentration, which indicates that the addition of clay enhances the near surface hardness of nanocomposite films.

Modulus of unpolished and polished injection molded nanocomposites has been compared before. Moduli values of both unpolished and polished samples are in close agreement except that the unpolished sample has larger standard deviation due to the surface roughness [48].

Results of modulus from unload and hardness from unload at different strain rates are shown in Figures 9(b) and $9(\mathrm{c})$. At all strain rate, compared to CN6F, modulus and hardness are higher for films with additives. Surface hardness and modulus slightly increase with increasing strain rate for CN6F and N6CF2 and N6CF10, which indicates increase in resistance of material to indentation.

Results of hardness profile are included in supplementary information (Figure S6). Initial uncertainty in hardness profile which is reported in earlier studies is due to indentation size effect $[48,49]$, or uncertainties in surface topology of films which is also evident in SEM micrographs. Also the standard deviation and coefficient of variation COV (tabulated in supplementary information Table S2) of results are very high for N6CF10 which is due to the change from dispersed, intercalated to agglomerated morphology with increased percentage of additives. 

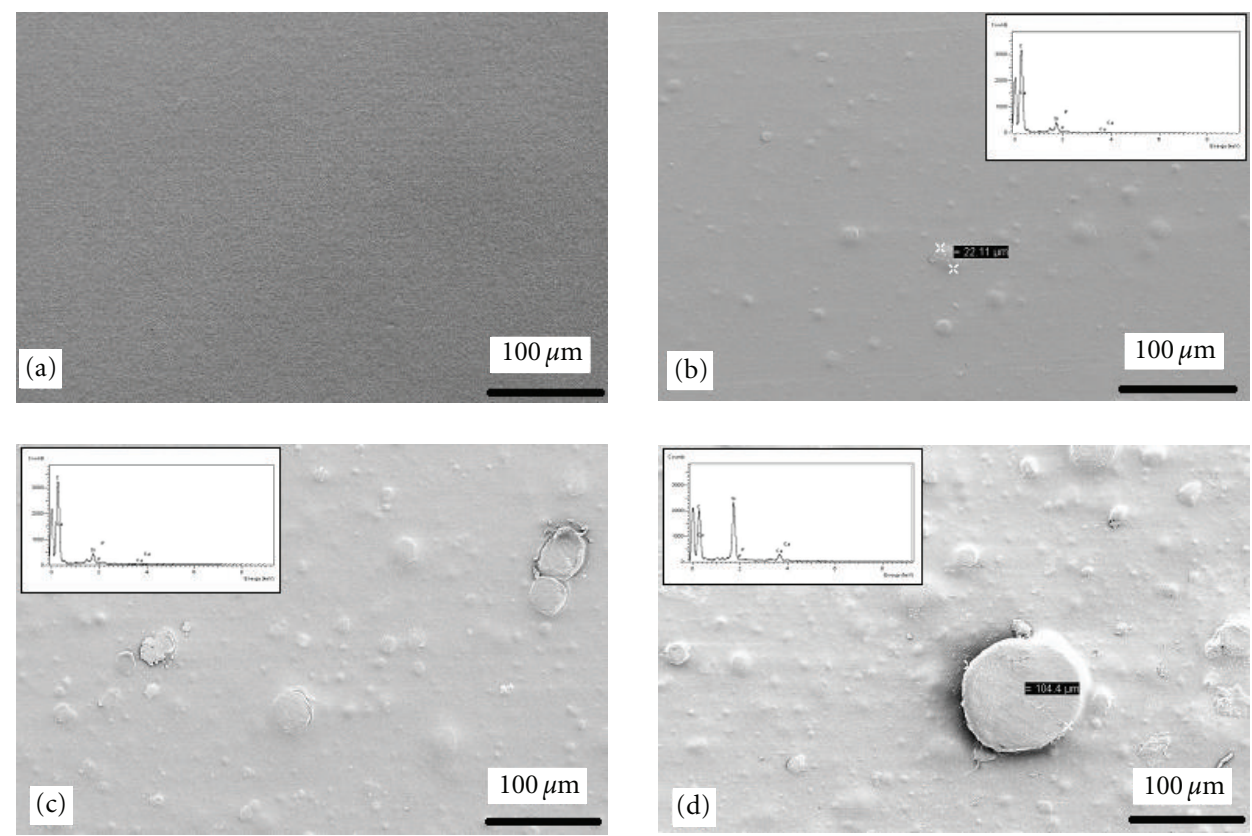

Figure 10: SEM micrograph of (a) CN6F, (B) N6CF2, (C) N6CF5, (d) N6CF10.

SEM micrographs of CN6F, N6CF2, N6CF5, and N6CF10 are shown in Figure 10. CN6F surface is relatively smoother compared to films with additives. Films N6CF5 and N6CF10 revealed increase in flaws and grooves on surface. SEM micrograph shows 20 to $104 \mu \mathrm{m}$ size particles on the surface. This may be due to nonuniform dispersion or agglomeration of clay platelets and protrusion from surface. The EDS scan of the film surface (shown in inset) with additives indicate increase in Si composition near surface.

Results of polarized optical micrographs are shown in Figure 11. CN6F formed spherulite of maximum attainable diameter $55 \mu \mathrm{m}$ (average of $n=15$ spherulites). Whereas for N6CF2, N6CF5, and N6CF10 fine grained texture was observed. This is due to the nanoconfinement and multiple nucleation effects. Similar results have been reported for nylon66/MWNT composites [46]. Average maximum attainable diameter of spherulite in case of sample with nanoclay additives could not be calculated because of very high nucleation density and small size of spherulites.

3.6. Atomic Force Microscopy (AFM). Detailed scientific principles and methods used to analyze the AFM tapping mode analysis and data interpretation are included in supplementary information. Nanoscale surface roughness of the films was calculated by section analysis of the height image. The section analysis of the height image indicated increase in nanoscale roughness for films with additives (results are included in Table 5). AFM tapping mode phase image for the different film samples is shown in Figure 12. Each image shows scan size of one micron. Since $\Delta \Phi$ clay $>\Delta \Phi$ nylon 6, AFM phase image can be used to map stiffness difference on the surface. The phase contrast image for N6CF2 and N6CF5 (shown in Figure 12) shows only small differences in phase. Phase contrast image of N6CF10 is significantly different from rest which is due to increase in surface stiffness and also overall increase in the presence of high modulus clay platelets near film surface.

3.7. Surface Energy. As evident from SEM, AFM phase image, and nanoindentation, near-surface stiffness increase due to overall increase in clay platelets near the surface and protrusion of nano-additives from the surface. This clay protrusion from the surface has significant impact on the surface energy and film wetting behavior. To estimate surface energy of films, contact angle test was used. Schematic of contact angle formation on the samples is shown in Figures 13(a) and 13(b). Results of contact angle are shown in Figure 13(c). Contact angle drops with increase in clay additives. Earlier studies report better dye affinity for the polypropylene fibers with clay platelets. We have shown that surface energy of even the polar nylon 6 films can be increased by incorporating the nanoclay additives.

At higher wt\% clay loading, it is difficult to disperse the additive through sample and additive forms highersize tactoids. TEM image in Figure 5 revealed increased agglomerate formation for N6CF10. Film retains its hardness and toughness till $5 \mathrm{wt} \%$ loading but beyond $5 \mathrm{wt} \%$, film shows brittle failure. This is because interaction between the clay platelets is weak compared to interaction between clay and nylon- 6 chain. So, during tear strength and tensile testing, these tactoids with voids act as weak spots and initiate craze causing overall decrease in elongation to break. TEM image (Figure 5) reconfirms the presence of these voids between platelets. Thus, beyond $5 \mathrm{wt} \%$, clay loading, nanocomposites morphology can be compared to conventional composite morphology due to presence of large agglomerates of platelets and insufficient interfacial adhesion between platelets and matrix [50]. Near-surface hardness 


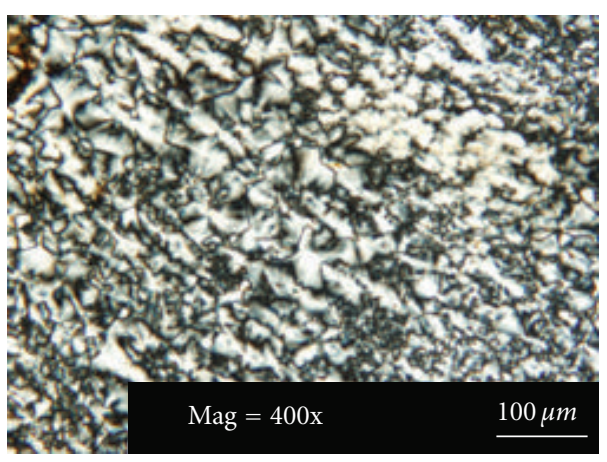

(a)

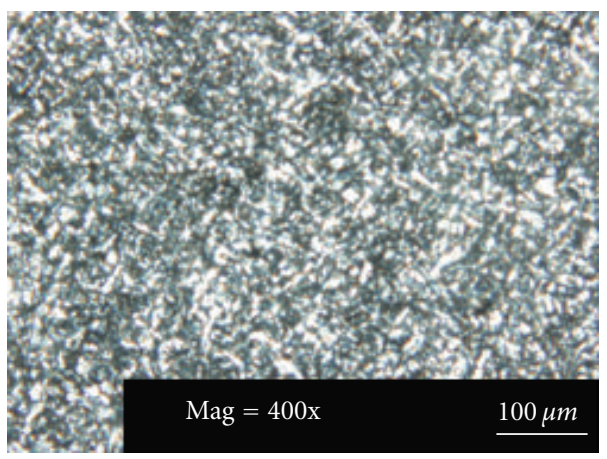

(c)

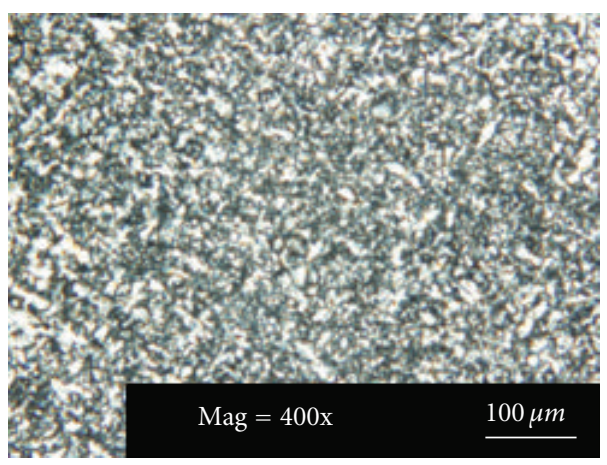

(b)

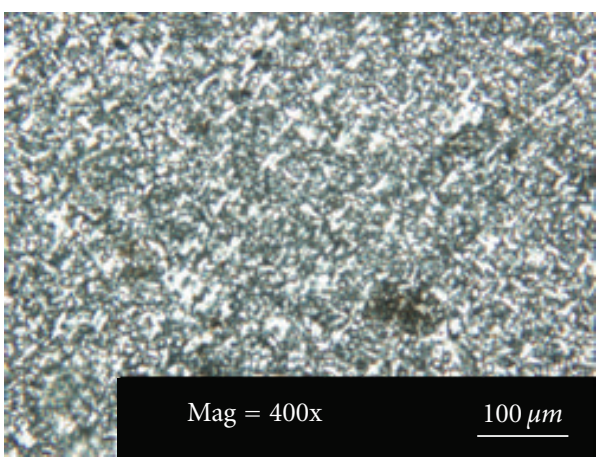

(d)

Figure 11: Polarized light micrographs of (a) CN6F, (b) N6CF2, (c) N6CF5, and (d) N6CF10.
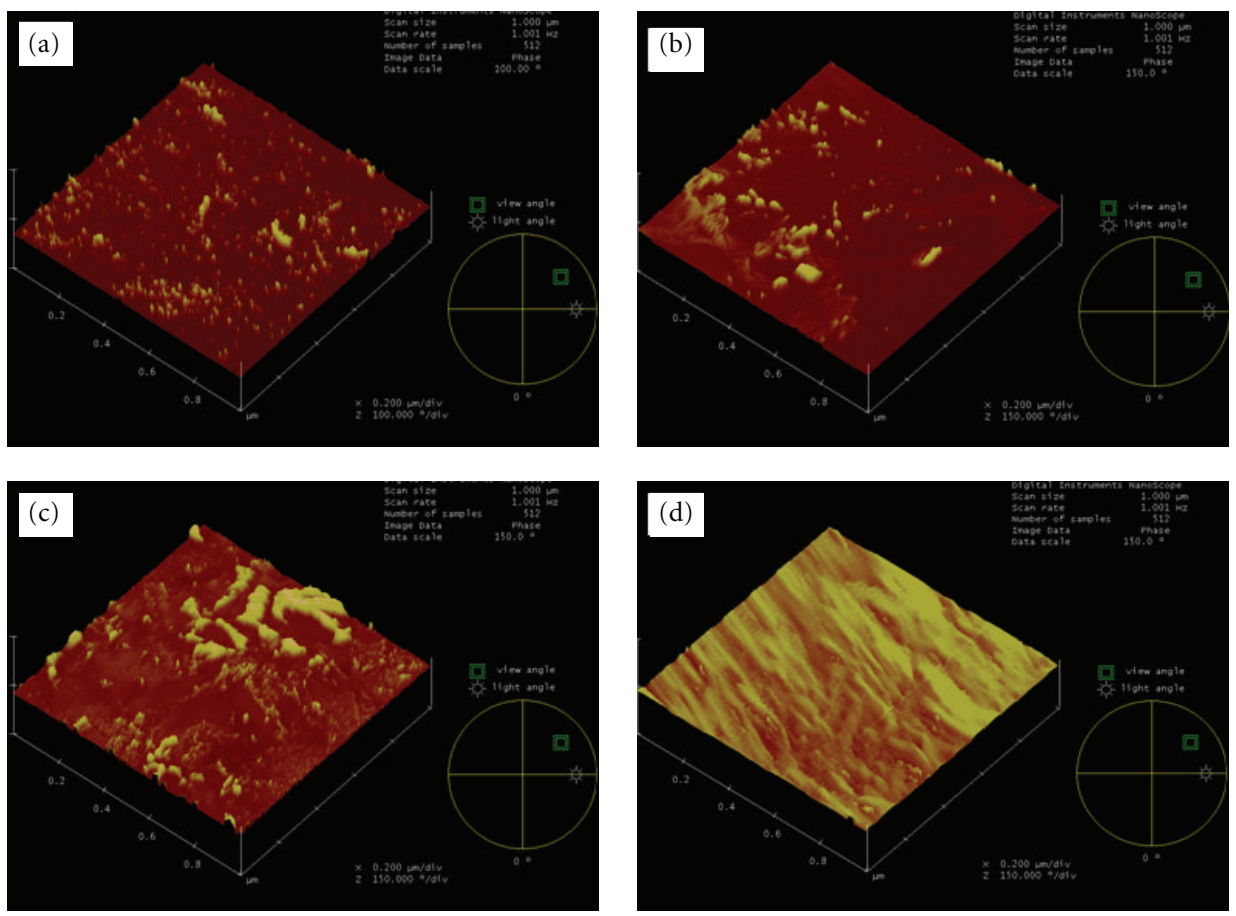

Figure 12: AFM image of (a) CN6F, (b) N6CF2 (film with $2 \mathrm{wt} \%$ clay), (c) N6CF5 (film with 5 wt\% clay), and (d) N6CF10 (film with $10 \mathrm{wt} \%$ clay). (Color figure can be viewed in the online issue). 


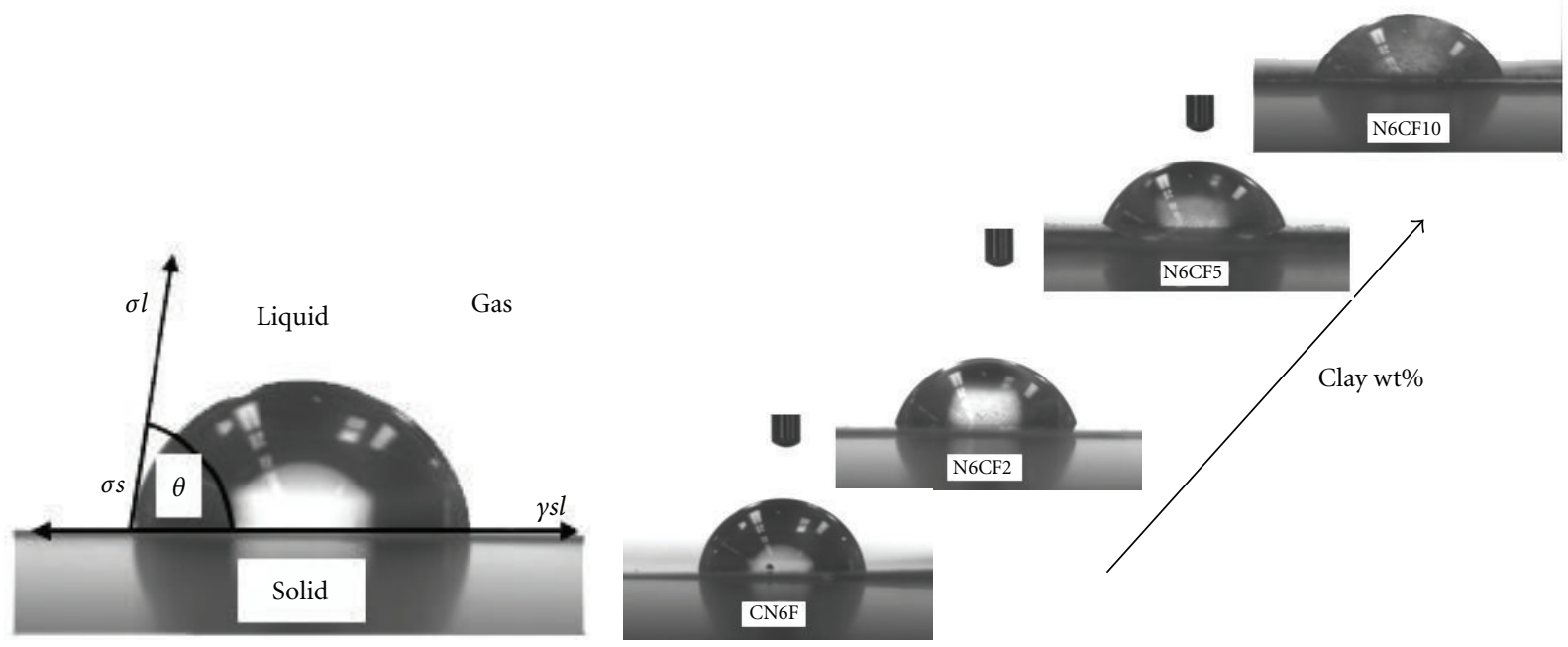

(a)

(b)

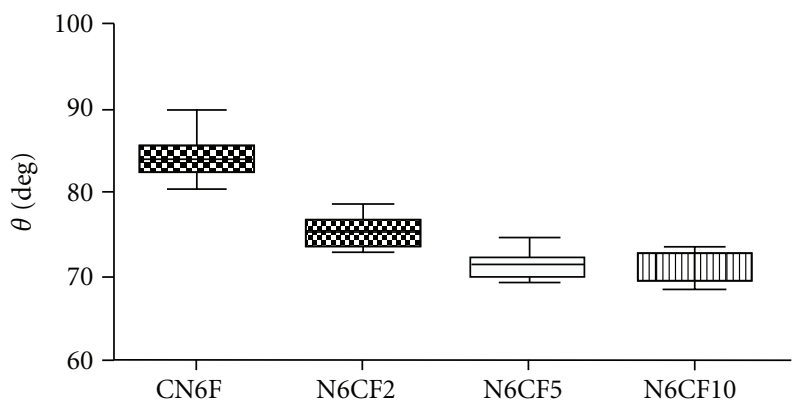

(c)

FIGURE 13: Results of contact angle analysis (a) contact angle formation on a solid surface according to YOUNG, (b) contact angle formation on different blown film samples, and (c) results of contact angle theta for sample with increasing wt\% clay.

and stiffness increases for all the nanocomposites because of presence of high modulus clay additives in surface as evident in SEM, AFM, and nanoindentation results. Increased clay platelet protrusion from the surface cause increased flaws, groves, and amorphous content [51]. Increased clay near surface increases the surface energy as shown in contact angle results.

\section{Conclusions}

Influence of increased add on level of nanoclay additives on the nanoscale and microscale morphology of the nylon6 blown films was investigated. Film toughness and hardness increased till $5 \mathrm{wt} \%$ additives add on, and beyond $5 \mathrm{wt} \%$, film becomes hard and brittle. TEM micrographs revealed good dispersion and intercalation for 2 and $5 \mathrm{wt} \%$ add on. At $10 \mathrm{wt} \%$, highly aggregated and intercalated morphology was observed. At higher-weight percentage, even though mechanical properties decreased due to micro-voids and groves on the surface, nanoscale stiffness and modulus were higher. Melting and crystallization behavior was also examined. Film with clay formed fine-grained spherulite.
Results show that clay acted as nucleating agent at all add on levels but the at higher weight percentages clay platelets hindered the secondary crystallization. In addition to increase in mechanical properties, clay addition leads to increases the surface energy and enhanced wetting.

\section{Acknowledgments}

The authors would like to thank Techmer PM, Clinton, TN for providing the blown films. The authors would like to thank small scale mechanical behavior group at the Department of Materials Science and Engineering, University of Tennessee Knoxville, TN MSE for providing assistance with the nanoindentation testing. Financial support from The Center for Materials Processing (CMP) at the University of Tennessee, Knoxville, is also appreciated.

\section{References}

[1] E. Picard, A. Vermogen, J. F. Gérard, and E. Espuche, "Barrier properties of nylon 6-montmorillonite nanocomposite membranes prepared by melt blending: influence of the clay content 
and dispersion state. consequences on modelling," Journal of Membrane Science, vol. 292, no. 1-2, pp. 133-144, 2007.

[2] E. P. Giannelis, "Polymer layered silicate nanocomposites," Advanced Materials, vol. 8, no. 1, pp. 29-35, 1996.

[3] J. W. Gilman, T. Kashiwagi, and J. D. Lichtenhan, "Nanocomposites: a revolutionary new flame retardant approach," SAMPE Journal, vol. 33, no. 4, pp. 40-46, 1997.

[4] Y. Kojima, A. Usuki, M. Kawasumi et al., "Mechanical properties of nylon 6-clay hybrid," Journal of Materials Research, vol. 8, no. 5, pp. 1185-1189, 1993.

[5] Y. Kojima, A. Usuki, M. Kawasumi, A. Okada, T. Kurauchi, and O. Kamigaito, "Sorption of water in nylon 6-clay hybrid," Journal of Applied Polymer Science, vol. 49, no. 7, pp. 12591264, 1993.

[6] R. A. Vaia, G. Price, P. N. Ruth, H. T. Nguyen, and J. Lichtenhan, "Polymer/layered silicate nanocomposites as high performance ablative materials," Applied Clay Science, vol. 15, no. 1-2, pp. 67-92, 1999.

[7] L. S. Loo and K. K. Gleason, "Investigation of polymer and nanoclay orientation distribution in nylon 6/montmorillonite nanocomposite," Polymer, vol. 45, no. 17, pp. 5933-5939, 2004.

[8] R. R. Hegde, J. E. Spruiell, and G. S. Bhat, "Different crystallization mechanisms in polypropylene-nanoclay nanocomposite with different weight percentage of nanoclay additives," Journal of Materials Research, vol. 27, no. 10, pp. 1360-1371, 2012.

[9] D. L. Hunter, K. W. Kamena, and D. R. Paul, "Processing and properties of polymers modified by clays," Mrs Bulletin, vol. 32, no. 4, pp. 323-327, 2007.

[10] A. Leuteritz, D. Pospiech, B. Kretzschmar et al., "Polypropylene-clay nanocomposites: comparison of different layered silicates," Macromolecular Symposia, vol. 221, pp. 53-61, 2005.

[11] "Product Bulletin/Closite," Southern clay products, inc., http://www.nanoclay.com/.

[12] S. W. Brindly and G. Brown, Eds., Crystal Structure of Clay Minerals and Their X-Ray Diffraction, Mineralogical Society, London, UK, 1980.

[13] P. Aranda and E. Ruiz-Hitzky, "Poly(ethylene oxide)-silicate intercalation materials," Chemistry of Materials, vol. 4, no. 6, pp. 1395-1403, 1992.

[14] D. J. Greenland, "Adsorption of polyvinyl alcohols by montmorillonite," Journal of Colloid Science, vol. 18, no. 7, pp. 647664, 1963.

[15] N. Hasegawa, H. Okamoto, M. Kawasumi, M. Kato, A. Tsukigase, and A. Usuki, "Polyolefin-clay hybrids based on modified polyolefins and organophilic clay," Macromolecular Materials and Engineering, vol. 280-281, pp. 76-79, 2000.

[16] P. H. Nam, P. Maiti, M. Okamoto, T. Kotaka, N. Hasegawa, and A. Usuki, "A hierarchical structure and properties of intercalated polypropylene/clay nanocomposites," Polymer, vol. 42, no. 23, pp. 9633-9640, 2001.

[17] M. Joshi and V. Viswanathan, "High-performance filaments from compatibilized polypropylene/clay nanocomposites," Journal of Applied Polymer Science, vol. 102, no. 3, pp. 21642174, 2006.

[18] K. Rogers, E. Takacs, and M. R. Thompson, "Contact angle measurement of select compatibilizers for polymer-silicate layer nanocomposites," Polymer Testing, vol. 24, no. 4, pp. 423427, 2005.

[19] L. Liu, Z. Qi, and X. Zhu, "Studies on nylon 6/clay nanocomposites by melt-intercalation process," Journal of Applied Polymer Science, vol. 71, no. 7, pp. 1133-1138, 1999.
[20] Y. Katoh and M. Okamoto, "Crystallization controlled by layered silicates in nylon 6-clay nano-composite," Polymer, vol. 50, no. 19, pp. 4718-4726, 2009.

[21] T. D. Fornes and D. R. Paul, "Crystallization behavior of nylon 6 nanocomposites,” Polymer, vol. 44, no. 14, pp. 3945-3961, 2003.

[22] S. Xie, S. Zhang, B. Zhao, H. Qin, F. Wang, and M. Yang, "Tensile fracture morphologies of nylon-6/montmorillonite nanocomposites," Polymer International, vol. 54, no. 12, pp. 1673-1680, 2005.

[23] G. S. Bhat, R. R. Hegde, M. G. Kamath, and B. Deshpande, "Nanoclay reinforced fibers and nonwovens," Journal of Engineered Fibers and Fabrics, vol. 3, no. 3, pp. 22-34, 2008.

[24] R. R. Hegde and G. S. Bhat, "Nanoparticle effects on structure and properties of polypropylene meltblown webs," Journal of Applied Polymer Science, vol. 115, no. 2, pp. 1062-1072, 2010.

[25] R. R. Hegde and G. S. Bhat, "Nanoparticle effects on the morphology and mechanical properties of polypropylene spunbond webs," Journal of Applied Polymer Science, vol. 118, no. 6, pp. 3141-3155, 2010.

[26] B. D. Cullity and S. R. Stock, Elements of X-Ray Diffraction, Prentice Hall, NJ, USA, 3rd edition, 2001.

[27] W. Weng, G. Chen, and D. Wu, "Crystallization kinetics and melting behaviors of nylon 6/foliated graphite nanocomposites," Polymer, vol. 44, no. 26, pp. 8119-8132, 2003.

[28] M. Mucha and Z. Królikowski, "Application of dsc to study crystallization kinetics of polypropylene containing fillers," Journal of Thermal Analysis and Calorimetry, vol. 74, no. 2, pp. 549-557, 2003.

[29] M. Avrami, "Kinetics of phase change. ii transformation-time relations for random distribution of nuclei," the Journal of Chemical Physics, vol. 8, no. 2, pp. 212-224, 1940.

[30] K. Mezghani and P. J. Phillips, "The $\gamma$-phase of high molecular weight isotactic polypropylene: iii. the equilibrium melting point and the phase diagram," Polymer, vol. 39, no. 16, pp. 3735-3744, 1998.

[31] S. N. Magonov, V. Elings, and M. H. Whangbo, "Phase imaging and stiffness in tapping-mode atomic force microscopy," Surface Science, vol. 375, no. 2-3, pp. L385-L391, 1997.

[32] J. F. Lübben, G. Fortunato, M. Halbeisen, S. Houis, M. Keller, and E. Körner, "Characterization of synthetic fibers using the atomic force microscope," Journal of Physics: Conference Series, vol. 61, no. 1, article no. 147, pp. 735-739, 2007.

[33] W. C. Oliver and G. M. Pharr, "Improved technique for determining hardness and elastic modulus using load and displacement sensing indentation experiments," Journal of Materials Research, vol. 7, no. 6, pp. 1564-1583, 1992.

[34] Y. Katoh and M. Okamoto, "Crystallization controlled by layered silicates in nylon 6-clay nano-composite," Polymer, vol. 50, no. 19, pp. 4718-4726, 2009.

[35] M. Alexandre and P. Dubois, "Polymer-layered silicate nanocomposites: preparation, properties and uses of a new class of materials," Materials Science and Engineering R, vol. 28, no. 1, pp. 1-63, 2000.

[36] R. Zbinden, Infrared Spectroscopy of High Polymers, Academic Press, New York, NY, USA, 1964.

[37] P. J. Yoon, T. D. Fornes, and D. R. Paul, "Thermal expansion behavior of nylon 6 nanocomposites," Polymer, vol. 43, no. 25, pp. 6727-6741, 2002.

[38] A. Dasari, Z. Z. Yu, Y. W. Mai, G. H. Hu, and J. Varlet, "Clay exfoliation and organic modification on wear of nylon 6 nanocomposites processed by different routes," Composites Science and Technology, vol. 65, no. 15-16, pp. 2314-2328, 2005. 
[39] W. M. Pitts, "The global equivalence ratio concept and the formation mechanisms of carbon monoxide in enclosure fires," Progress in Energy and Combustion Science, vol. 21, no. 3, pp. 197-237, 1995.

[40] "Cloisite Nanoclays," http://www.nanoclay.com/benefits2.asp.

[41] S. Zhang, T. R. Hull, A. R. Horrocks et al., "Thermal degradation analysis and XRD characterisation of fibre-forming synthetic polypropylene containing nanoclay," Polymer Degradation and Stability, vol. 92, no. 4, pp. 727-732, 2007.

[42] X.-L. Bai, Y.-M. Wang, Q. LI, and C.-Y. Shen, "Assessment of crystallizability of the PET/Clay nanocomposites by DSC," Journal of Zhengzhou University (Engineering Science), no. 3, 2002.

[43] M. Ito, K. Mizuochi, and T. Kanamoto, "Effects of crystalline forms on the deformation behaviour of nylon-6," Polymer, vol. 39, no. 19, pp. 4593-4598, 1998.

[44] D. M. Lincoln, R. A. Vaia, Z. G. Wang, and B. S. Hsiao, "Secondary structure and elevated temperature crystallite morphology of nylon-6/layered silicate nanocomposites," Polymer, vol. 42, no. 4, pp. 1621-1631, 2001.

[45] R. R. Hegde, Structure and properties of nanoclay reinforced polymer films, fibers and nonwovens, Ph.D. dissertation, University of Tennessee, 2009.

[46] L. Li, C. Y. Li, C. Ni, L. Rong, and B. Hsiao, "Structure and crystallization behavior of nylon 66/multi-walled carbon nanotube nanocomposites at low carbon nanotube contents," Polymer, vol. 48, no. 12, pp. 3452-3460, 2007.

[47] Q. Yuan, S. Awate, and R. D. K. Misra, "Nonisothermal crystallization behavior of polypropylene-clay nanocomposites," European Polymer Journal, vol. 42, no. 9, pp. 1994-2003, 2006.

[48] L. Shen, I. Y. Phang, L. Chen, T. Liu, and K. Zeng, "Nanoindentation and morphological studies on nylon 66 nanocomposites. i. effect of clay loading," Polymer, vol. 45, no. 10, pp. 3341-3349, 2004.

[49] W. D. Nix and H. Gao, "Indentation size effects in crystalline materials: A law for strain gradient plasticity," Journal of the Mechanics and Physics of Solids, vol. 46, no. 3, pp. 411-425, 1998.

[50] R. R. Hegde and G. S. Bhat, Effect of Nanoclay Reinforcement on Structure and Properties of Nylon 6 films, Fiber Society, 2007.

[51] X. Zhang, M. Yang, Y. Zhao et al., "Polypropylene/montmorillonite composites and their application in hybrid fiber preparation by melt-spinning," Journal of Applied Polymer Science, vol. 92, no. 1, pp. 552-558, 2004. 

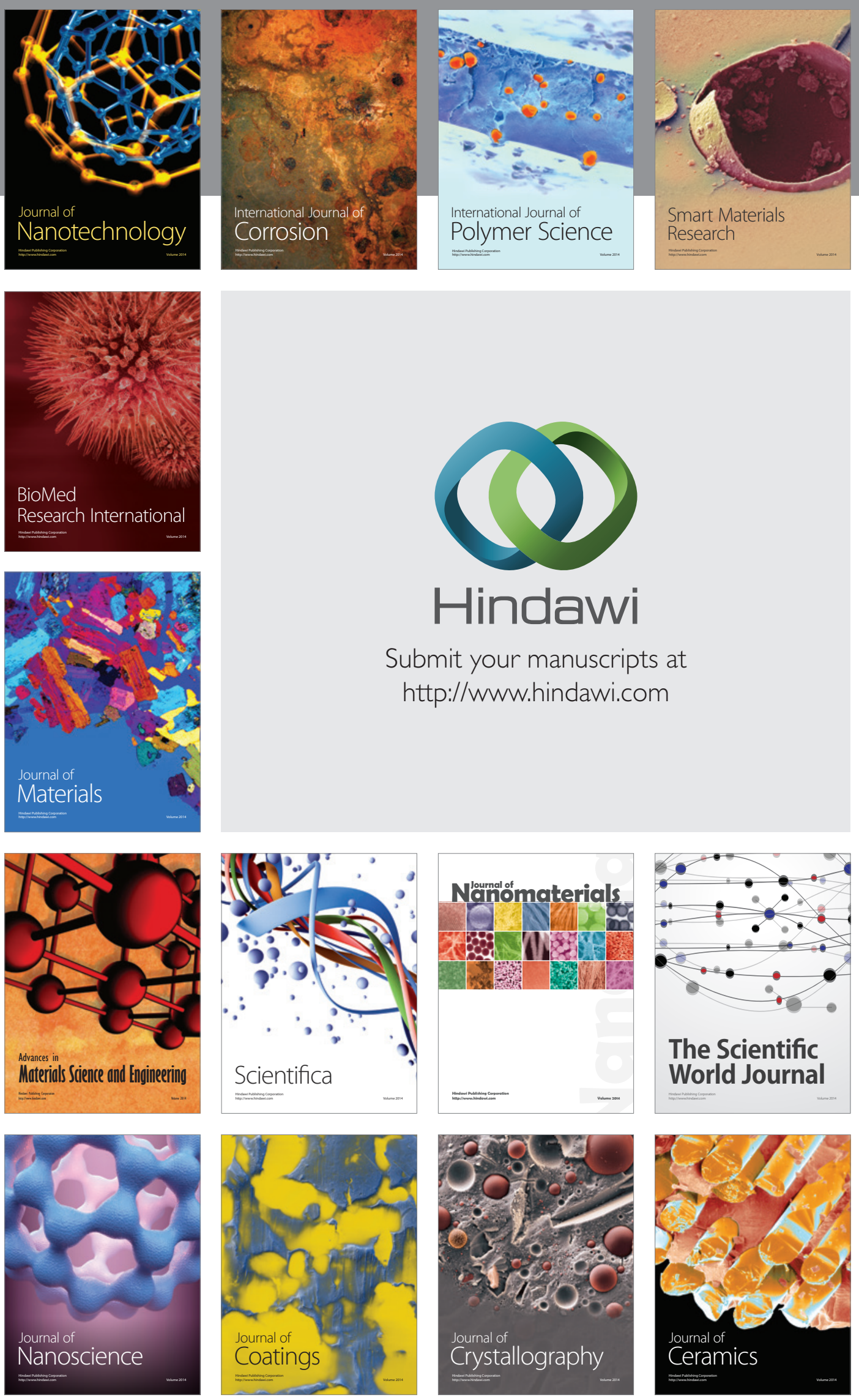

The Scientific World Journal

Submit your manuscripts at

http://www.hindawi.com

\section{World Journal}

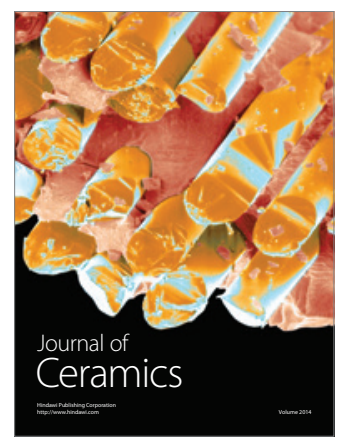

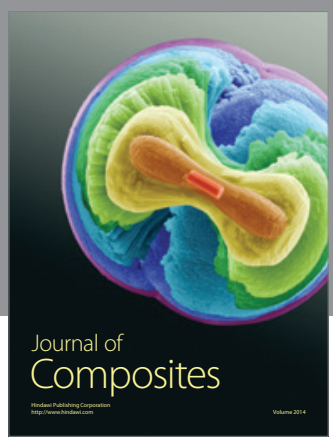
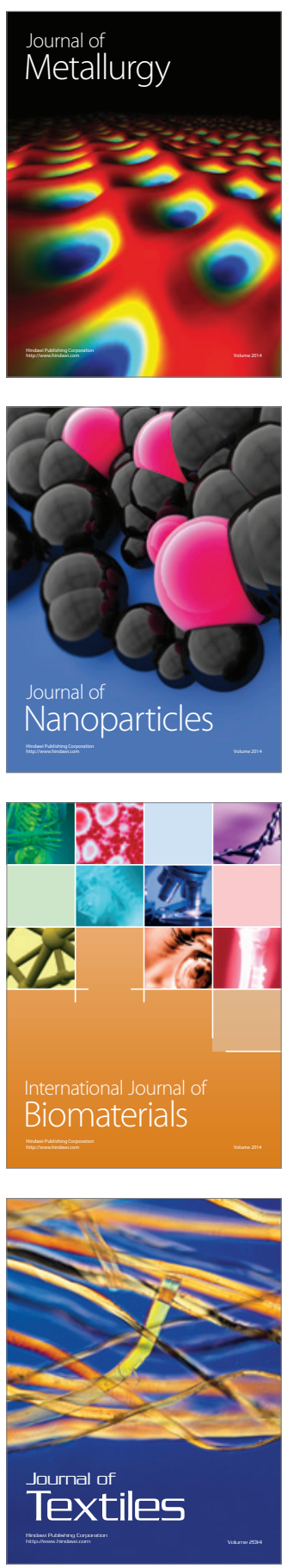